\title{
The Impact of the Flexibility of Quality Contracts on the Quality Performance of Organizations: Moderating Effect Based on Quality Knowledge Distance
}

\author{
Li Xue ${ }^{1, *}$, Liu Qiang ${ }^{2}$, Li Bing ${ }^{1}$, Guo Yu ${ }^{3}$ \\ ${ }^{1}$ School of Economics, Liaoning University of Technology, Jinzhou, Liaoning, China \\ ${ }^{2}$ School of Management, Liaoning University of Technology, Jinzhou, Liaoning, China \\ ${ }^{3}$ School of Economics and Management, Harbin Engineering University, Heilongjiang, China
}

Keywords: Quality Contract Flexibility, Organizational Quality Performance, Paradox Cognition, Controlling Accidental Quality Knowledge Leakage, Quality Knowledge Distance.

Abstract: Measuring the quality of a company's operations is the key to judging its existence. Based on the flexibility of the quality contract of the enterprise, this study studies its mechanism that affects the quality performance of the organization. This study starts from the flexibility of quality contract, and studies its impact path on organizational quality performance. It takes quality contract flexibility as independent variable, organizational quality performance as dependent variable, paradox cognition and control accidental quality knowledge leakage as intermediate variable and quality knowledge distance as Moderator. The empirical results show that the flexibility of the quality contract will affect the quality performance of the organization, the paradox cognition and the control of accidental knowledge leakage play a positive intermediary role, and the quality knowledge distance plays a moderating role. That is to say, when signing a flexible contract, an enterprise can improve its quality performance by improving the awareness of paradox and strengthening the control of accidental knowledge leakage.

\section{Introduction}

For the study of contract flexibility, on the one hand, Chiara and Kokkaew [1] found from the perspective of the first social exchange theory that it was found that enhancing contract flexibility can make risk transfer [2] more efficient and reasonable. With the deepening of study, some scholars found that the flexible clauses in the contract cannot be deleted, and the flexibility of the contract gives a solution [3]. Carlos and Marques [4] found on the basis of their predecessors that the most important function of contract flexibility is to provide strategic tools. On the other hand, Levin and Tadelis [5], Steven [6] analyzed price compensation from the perspective of public contract price clauses and private contract price clauses. At the same time, some scholars [7] believe that giving full play to contractual flexibility to give actors some exercise power can increase the response speed to uncertain events, reasonably establish a trust mechanism between 
parties, promote contract implementation, and achieve stated goals. Kujala [8] and others believe that the involvement of non-rigid factors in the contract is an important measure to achieve the current goal. The study of Roehrich and Lewis [9] found that the contract is subject to the law, which has the effect of restraining the behavior of both parties, thereby guaranteeing corporate performance.

The predecessors mostly surveyed contract flexibility in project risk, and did not study the impact of quality contract flexibility on performance at the enterprise level. Therefore, from the perspective of contract flexibility, this study studies its influence on organizational quality performance under the influence of mediating adjustment of variables such as paradox cognition.

\section{Theoretical Basis and Hypothetical Deduction}

The purpose of this study is to make the following assumptions.

\subsection{Quality Contract Flexibility and Organizational Quality Performance}

Contracts [10] are both rigid and flexible. The quality contract is a negotiation between the two parties on the quality issue. However, the two cooperating parties often have differences and contradictions on this key issue. Some scholars [11] conducted research on quality contract flexibility and found that contract flexibility has obvious effects in modern enterprise management, forming management flexibility [12], thereby accelerating the speed of enterprise information transmission and showing the advantages of flexible contract management. Similarly, Cruz and Rui [4] also found that when certain conditions are met, adding some flexible settings to the quality contract can significantly improve management efficiency and reduce the uncertainty of rigid characteristics in the contract. In fact, the management, innovation, and cost control of social capital are even more advantageous [13]. According to the analysis of Aghion [14], a contract containing clauses such as secondary negotiation, price, and benefit distribution can reduce operating costs, share project implementation risks, and improve corporate performance. Zhang Lei [15] also believes that flexible contracts can help achieve management flexibility, which in turn has an impact on contracts. In terms of corporate costs, Bajari [16] and Susarla [17] conducted specific investigation. Based on this, this study makes the following assumptions.

H1: The quality contract flexibility can significantly promote the quality performance of the organization.

\subsection{The Mediating Role of Paradox Cognition}

Paradox theory [18] points out that there is a conflicting and mutually soluble decision-making situation in enterprises. Paradox cognition refers to the process of identifying and accommodating paradoxes [19], which can help companies identify and accept potential paradoxes faced by enterprises, and find a way to resolve paradoxes to achieve a state of equilibrium. The higher the level of paradox cognition, the more objective the perception of things is, and the easier it is to discern organizational paradoxes [20]. Smith and Tushman [21] proposed that only fully identifying and using cognitive paradoxes in an enterprise can make the various decision-making subsystems of the enterprise coordinate with each other, so it is important to differentiate, balance and integrate cognitive paradoxes. The cognitive paradox promotes the correctness of corporate strategic decisions from differentiation to integration, from whole to zero and then from zero to whole [22]. Wei Zesheng [23] obtained the results of paradox cognition on green performance after Peng [24], and then studied the paradox cognition on green performance [25] from paradox theory and system theory. Simth and Lewis [26] believe that the paradox cognition profoundly affects the company's 
response strategy to the performance paradox. Hahn [27] believe that the paradox cognitive framework can guide companies to focus on green performance, financial performance and social performance at the same time.

H2: Paradox cognition is positively affecting organizational quality performance.

Paradox cognition is actually the degree of recognition, acceptance, accommodation and cognition of both parties to a conflict. In the course of business operation, the quality contract signed is to balance the contradiction and connection between the two parties in terms of quality management. The GHM proposed by Hart [28], Grossman, Moore [29] believes that not only a specific right should be clarified in a flexible contract, but also the distribution of rights due to problems should be clarified. The two rights are relative and mutual, and the dialectical relationship between the two rights is fully shown in the flexible contract, and clearly expressed in the contract, so that the paradox reaches an equilibrium state. Based on this hypothesis.

H3: The flexibility of quality contract is promoting the paradox recognition.

H4: Paradox cognition mediates the flexibility of quality contracts and organizational quality performance.

\subsection{Controlling Accidental Quality Knowledge Disclosure}

Regarding knowledge leakage [30], Grossman [31] was first proposed, but a clear definition was given. The specific concept is defined by Li and Zhang [32], and it is proposed that knowledge leakage is knowledge leakage during knowledge sharing [33]. As for how knowledge leakage occurs, some scholars have conducted survey and found that job-hopping of highly educated employees will seriously damage the normal operation of the original company, and the employment of non-regular employees also increases the probability of knowledge leakage [34]. Improper management measures within the enterprise will inevitably cause employees to have negative emotions, which may lead to employees leaking organizational secrets [35].

According to whether the knowledge is intentionally leaked, knowledge leakage can be divided into active and accidental knowledge leakage [36]. The so-called accidental knowledge leakage refers to the accidental leakage of core knowledge within the organization by enterprise employees [37]. This study believes that before a company signs a contract with a partner, employees may intentionally or unintentionally disclose business-related business knowledge. Chen Wei analyzed the impact of unexpected knowledge leakage on innovation performance [36]. The management and control of accidental quality knowledge leakage and keeping their own quality of related products (services) within the enterprise will help the cooperative enterprises to take the initiative in negotiations. Based on this, hypotheses are proposed.

H5: Controlling accidental quality knowledge leakage has an impact on organizational quality performance.

H6: Controlling accidental quality knowledge leakage has a mediating effect on the quality contracts flexibility and organizational quality performance.

\subsection{Moderating Effect of Quality Knowledge Distance}

In the existing study, some scholars believe that knowledge distance plays a negative regulating role in the process of knowledge governance and innovation performance [38]. Commings [39] pointed out that the so-called knowledge distance refers to the disparity shown by the knowledge source and the knowledge sink when receiving and processing the same kind of knowledge. The proposition of the distance of quality knowledge enables both partners to measure the quality knowledge, pay attention to the ratio of quality knowledge, and correctly match the appropriate knowledge base can effectively reduce the cost of both parties [40] and promote the effective conclusion of the contract. 
In the process of knowledge transformation, the mutual transformation of different forms of knowledge will cause a certain degree of gap in knowledge identification and knowledge application [41]. At the same time, the quality knowledge distance can be the degree of difference in specific quality elements [42]. It can also be understood as the degree of difference between knowledge requirements and knowledge base in organizational quality [43], or the difference in knowledge structure [44].Chen Tao, Wang Tienan [45], proposed that the knowledge distance of an organization should include the distance between the internal and external knowledge bases of the organization. When the level of internal knowledge is higher than external knowledge, the knowledge level of the knowledge demanded is to absorb and utilize the knowledge passed by the knowledge supplier and create new knowledge [46]. The greater the distance between quality knowledge and the greater the possibility of knowledge leakage. The impact of the organization's organizational quality performance is also more obvious.

H7: Quality knowledge distance plays a moderating role in the flexibility of quality contracts and organizational quality performance.

H8: Mediated role of distance between quality knowledge and paradox cognition.

H9: The distance between quality knowledge and the control of accidental quality knowledge leakage to form a regulated intermediary role.

\subsection{Conceptual Model}

The hypothetical model derived from the above theory is shown as follows.

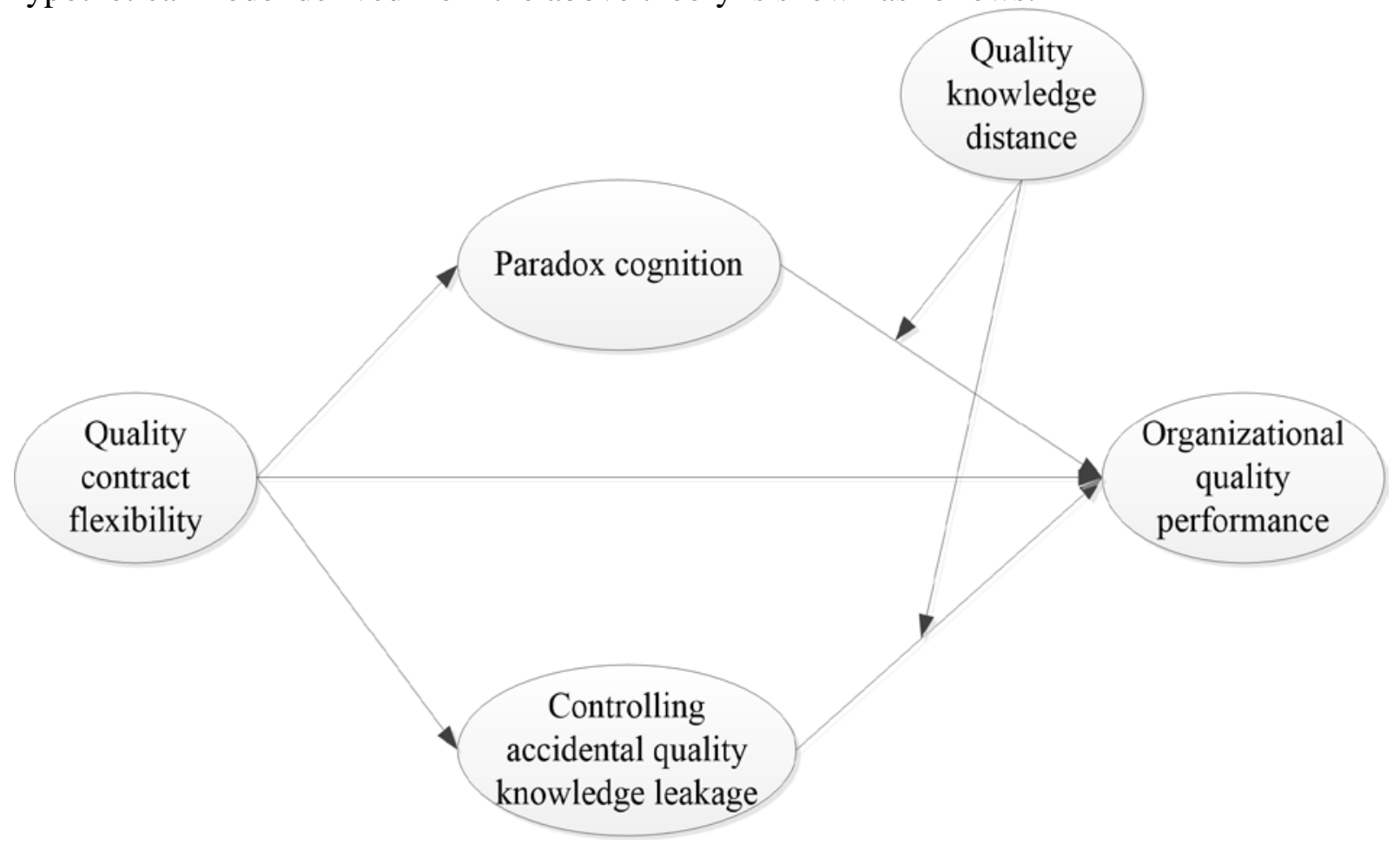

Figure 1: Conceptual model.

\section{Research Design}

In order to conduct an empirical analysis, a series of investigations are carried out. 


\subsection{Research Sample}

This study takes the internal, middle, and senior managers of high-tech enterprises in the eastern region as the survey objects, mainly using on-site surveys, commissioned surveys, and online surveys to issue questionnaires. A total of 455 questionnaires were issued, 322 valid questionnaires were received. Except that the questionnaires were not collected, there were 89 invalid questionnaires, including extreme questionnaires and incomplete questionnaires. The recovery rate was $70.77 \%$.

From the distribution of the samples, it can be seen that the respondents are mainly grass-roots and middle-level management personnel, accounting for $45.03 \%$ and $40.99 \%$ respectively, and senior management personnel account for $13.98 \%$; males account for $56.83 \%$, females account for 43.17\%, High school education and below accounted for $11.49 \%$, junior college accounted for $15.22 \%$, undergraduate accounted for $61.49 \%$, and survey and higher education was $11.80 \%$, of which the bachelor's degree mainly. Among the companies surveyed, $8.39 \%$ of the enterprises have been established for less than 3 years, $20.50 \%$ for $3-10$ years, $32.91 \%$ for $10-20$ years, and $38.21 \%$ for more than 20 years, most of which are over 10 years. Enterprises accounted for $26.71 \%$, private enterprises accounted for $48.45 \%$, joint ventures accounted for $17.39 \%$, and other enterprises accounted for $7.45 \%$.

Table 1: Distribution of demographic characteristics of the sample.

\begin{tabular}{|c|c|c|c|c|c|}
\hline Feature & Category & Proportion (\%) & Feature & Category & Proportion (\%) \\
\hline \multirow{2}{*}{ Survey object gender } & Male & 56.83 & \multirow{4}{*}{ Business age } & Under 3 years & 8.39 \\
\hline & Female & 43.17 & & 3-10 years & 20.50 \\
\hline \multirow{4}{*}{ Education level } & Below high school & 11.49 & & $10-20$ years & 32.91 \\
\hline & Specialist & 15.22 & & Over 20 years & 38.20 \\
\hline & Undergraduate & 61.49 & \multirow{4}{*}{ Business nature } & State-owned enterprise & 26.71 \\
\hline & Graduate and above & 11.80 & & Private Enterprise & 48.45 \\
\hline \multirow{5}{*}{ seniority } & Less than 1 year & 13.04 & & Joint venture & 17.39 \\
\hline & $1-3$ years & 21.12 & & other & 7.45 \\
\hline & 3-5 years & 33.85 & \multirow{3}{*}{ Current position } & Primary manager & 45.03 \\
\hline & 5-10 years & 22.36 & & Middle managers & 40.99 \\
\hline & More than 10 years & 9.63 & & Senior management & 13.98 \\
\hline
\end{tabular}

\subsection{Variable Selection and Measurement}

This study uses domestic and foreign mature scales for the measurement of survey variables. The quality contract flexibility in this study was developed using Zhu Fangwei's [47] scale for contract flexibility. Organizational quality performance is borrowed from Sun Panshi's [48] sutdy. Based on Smith and Lewis [26] and Wei Zesheng's [23] survey on paradox cognition, this study develops six indicators to measure paradox cognition. On the basis of the measurement scale measurement of accidental knowledge leaks by Li Zihanxin [49] and others, the scale is developed to obtain a scale of controlling accidental quality knowledge leaks. The quality knowledge distance is measured using the scales developed by Cummings [40] and Zhan Xiangdong [50].

Table 2: Variable measures.

\begin{tabular}{|c|c|}
\hline Variable & References \\
\hline Quality contract flexibility & Zhu Fangwei (2018) \\
\hline Organizational quality performance & Sun Panshi (2012) \\
\hline Paradox cognition & Smith and Lewis (2011), Wei Zesheng (2018) \\
\hline Controlling accidental quality knowledge leaks & Li Zihan Xin (2019) \\
\hline Quality knowledge distance & Cummings (2003), Zhan Xiangdong (2019) \\
\hline
\end{tabular}




\subsection{Reliability and Validity Tests of Variables}

In this study, SPSS22 is used to test the reliability and validity.

Table 3: Reliability and validity.

\begin{tabular}{|c|c|c|c|c|c|c|c|}
\hline Variable & KMO & Bartlett Chi Ssquare & P & CITC & Cronbach’s Coefficient & AVE & $\sqrt{\text { AVE }}$ \\
\hline Quality contract flexibility & 0.836 & 1817.797 & 0.000 & 0.966 & 0.983 & 0.753 & 0.868 \\
\hline Organizational quality performance & 0.856 & 1568.430 & 0.000 & 0.985 & 0.981 & 0.730 & 0.855 \\
\hline Paradox cognition & 0.799 & 2106.906 & 0.000 & 0.965 & 0.983 & 0.719 & 0.849 \\
\hline Controlling accidental quality knowledge leaks & 0.500 & 370.772 & 0.000 & 0.931 & 0.987 & 0.913 & 0.956 \\
\hline Knowledge distance & 0.858 & 1740.011 & 0.000 & 0.944 & 0.985 & 0.914 & 0.956 \\
\hline
\end{tabular}

As can be seen from the above table, the KMO value of all variables are above 0.5 , the cronbach's coefficients are also above 0.9 , the CITC values are also around 0.9 , indicating that the scale data has good reliability.

Validity mainly includes content, convergence, and differential validity. Most of the scales in this study refer to scales that have been used many times, so the content reliability of the scale can be passed. And according to the item measurement table, it can be known that the factor load of each item is higher than 0.5 , and the combination reliability is higher than the test standard, so the scale's convergence reliability is also good. The discriminant validity is compared with the correlation coefficient and the square root of ave. If the correlation coefficient is smaller than each variable, it indicates that Scale difference validity is better.

\section{Hypothesis Testing and Empirical Analysis}

To verify whether the hypothesis is true, analyze the collected data.

\subsection{Main Effect Test}

First verify the main effect analysis.

Table 4: Regression coefficient of quality contract flexibility to organizational quality performance.

\begin{tabular}{|c|c|c|}
\hline Regression equation & \multicolumn{2}{|c|}{ Coefficient test } \\
\hline & SE & $\mathrm{t}$ \\
\hline $\mathrm{Y}=0.964 \mathrm{X}$ & 0.015 & 65.251 \\
\hline
\end{tabular}

As can be seen from the above table, the flexibility of the quality contract has a significant positive impact on the quality performance of the organization. For each additional unit of explicit knowledge combined nuclear transformation unit, there will be an increase of 0.964 units of the effectiveness of the knowledge innovation proprietary system, so H1 holds.

\subsection{Mediation Effect Test}

Next, verify the mediation effect.

From the analysis, the direct effect of quality contract flexibility on organizational quality performance is 0.2203 , the effect of cognitive paradox on organizational quality performance is 0.7901, and the indirect effect of quality contract flexibility through paradox cognition on 
organizational quality performance is 0.7428 . It shows that the mediating effect of cognitive paradox is significant, H2, H3, H4 hold, the specific path diagram is shown below.

Table 5: The mediating role of cognitive paradox.

\begin{tabular}{|c|c|c|c|c|c|}
\hline & Regression equation & \multicolumn{2}{|c|}{ Coefficient test } & \multicolumn{2}{c|}{ 95\% confidence interval } \\
\hline & & $\mathrm{SE}$ & $\mathrm{t}$ & Upper limits & lower limits \\
\hline Step1 & $\mathrm{Y}=0.964 \mathrm{X}$ & 0.015 & 65.251 & & \\
\hline Step2 & $\mathrm{Y}=0.987 \mathrm{M}_{1}$ & 0.009 & 110.306 & & \\
\hline Step3 & $\mathrm{M} 1=0.959 \mathrm{X}$ & 0.016 & 60.625 & & \\
\hline \multirow{2}{*}{ Step4 } & $\mathrm{Y}=0.2203 \mathrm{X}+0.7901 \mathrm{M}_{1}$ & 0.0291 & 26.5938 & 0.7317 & 0.8486 \\
\hline & & 0.0297 & 7.5630 & 0.1630 & 0.2776 \\
\hline
\end{tabular}

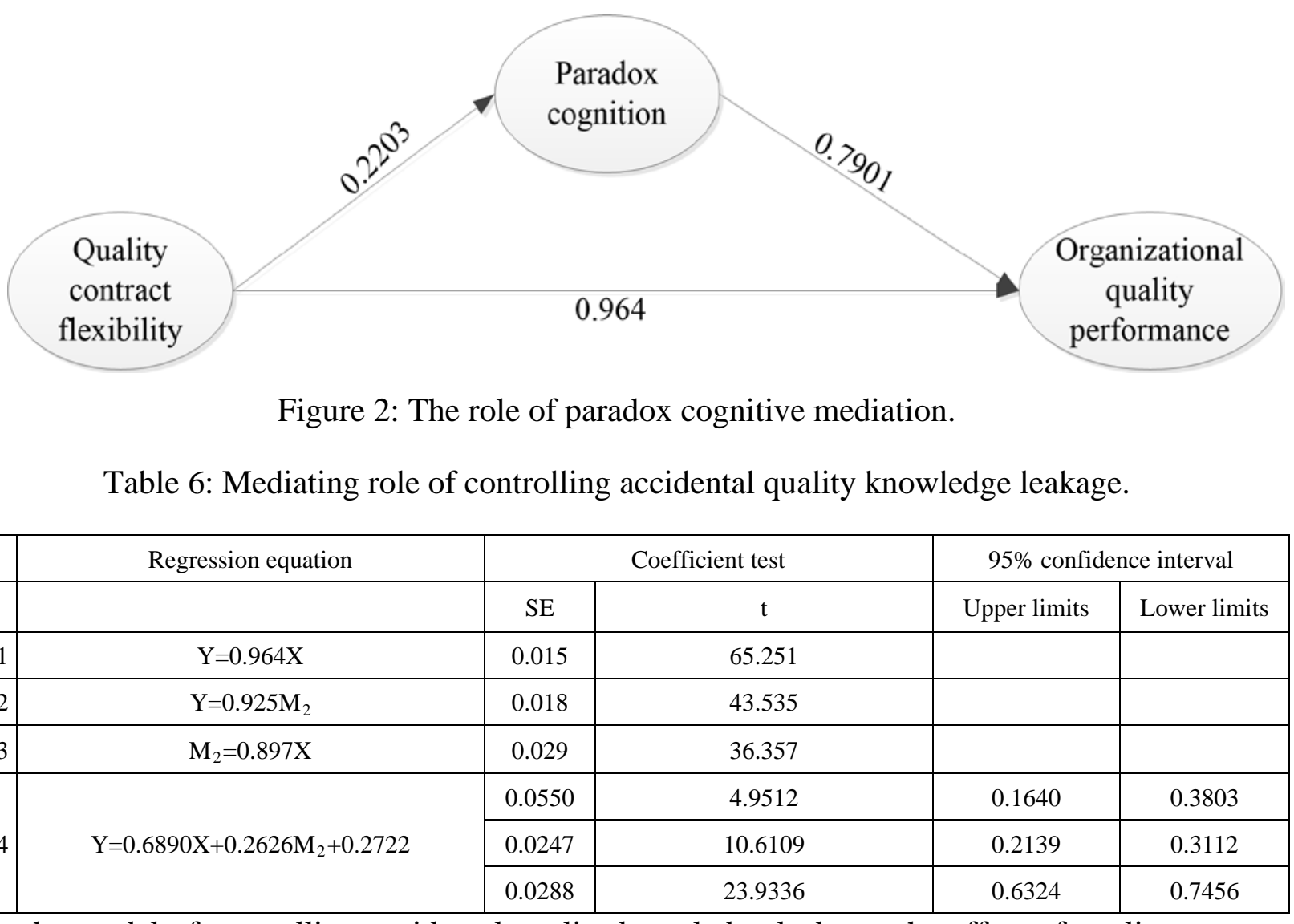

In the model of controlling accidental quality knowledge leakage, the effect of quality contract flexibility on organizational quality performance is 0.6890 , and the effect of controlling accidental quality knowledge leakage on organizational quality performance is 0.2626 . Indicating that the intermediary effect is significant, and $\mathrm{H} 5$ and $\mathrm{H} 6$ are established. The path diagram is as follows. 


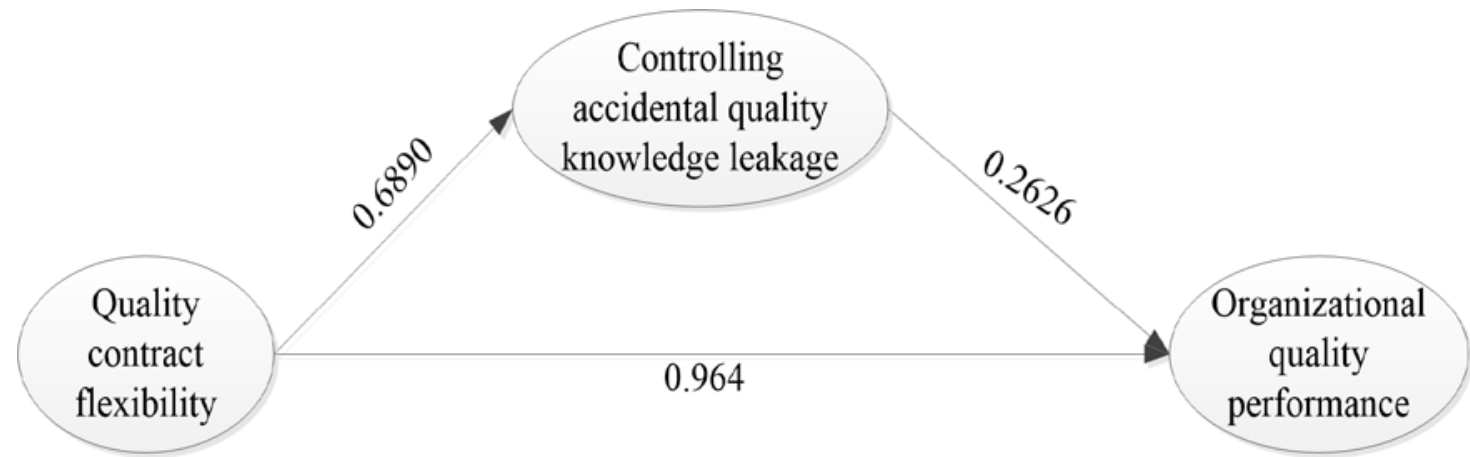

Figure 3: Intermediary paths for controlling accidental quality knowledge leakage.

\subsection{Moderating Effect Test}

Finally verify the regulation effect.

Table 7: Moderating effect of quality knowledge distance.

\begin{tabular}{|c|c|c|c|c|c|}
\hline & Regression equation & $\mathrm{R}_{1}{ }^{2}$ & $\mathrm{R}_{2}{ }^{2}$ & $* \mathrm{R}^{2}$ & $\mathrm{P}$ \\
\hline Step1 & $\mathrm{Y}=0.925 \mathrm{~W}$ & 0.855 & & & 0.000 \\
\hline Step2 & $\mathrm{Y}=0.837 \mathrm{X}+0.135 \mathrm{~W}$ & 0.932 & & & 0.000 \\
\hline Step3 & $\mathrm{Y}+0.9916 \mathrm{X}+0.2924 \mathrm{~W}+0.0400 \mathrm{WX}-0.3789$ & & 0.9515 & 0.0205 & 0.000 \\
\hline
\end{tabular}

The regression coefficient of the interaction term between the quality knowledge distance and the quality contract flexibility is significant, and the interaction term does not contain 0 in the $95 \%$ confidence interval [-0.0602, -0.0198] and the interaction term P value is less than 0.0001 , so $\mathrm{H7}$ is true.

\subsection{Adjusted Mediation Effect Test}

The regulated intermediary is formed due to the structure, the analysis is as follows.

Table 8: Mediated role of distance between quality knowledge and paradox cognition.

\begin{tabular}{|c|c|c|c|c|}
\hline & Regression equation & \multicolumn{3}{|c|}{ Coefficient test } \\
\hline & paradox cognition & $\mathrm{SE}$ & $\mathrm{t}$ & $\mathrm{P}$ \\
\hline \multirow{2}{*}{ Step1 } & \multirow{2}{*}{$\mathrm{Y}=0.837 \mathrm{X}+0.135 \mathrm{~W}$} & 0.044 & 19.072 & 0.000 \\
\hline & & 0.0340 & 3.079 & 0.000 \\
\hline \multirow{2}{*}{ Step2 } & \multirow{2}{*}{$\mathrm{M}_{1}=1.026 \mathrm{X}-0.071 \mathrm{~W}$} & 0.047 & 21.602 & 0.000 \\
\hline & & 0.043 & -1.496 & 0.136 \\
\hline & controlling accidental quality knowledge leakage & & & \\
\hline \multirow{2}{*}{ Step1 } & \multirow{2}{*}{$Y=0.837 X+0.135 W$} & 0.044 & 19.072 & 0.000 \\
\hline & & 0.0340 & 3.079 & 0.000 \\
\hline \multirow{2}{*}{ Step2 } & \multirow{2}{*}{$\mathrm{M}_{2}=0.106 \mathrm{X}+0.839 \mathrm{~W}$} & 0.067 & 1.841 & 0.067 \\
\hline & & 0.062 & 14.551 & 0.000 \\
\hline
\end{tabular}

As shown in the table above, the regression coefficient of the quality knowledge distance to the cognitive paradox is -0.1496 , it fails the test. So H8 is not true. The regression coefficient of the 
quality contract flexibility to control the accidental quality knowledge leakage is 0.106 , and the $\mathrm{p}$ value is 0.067 , which is greater than the significance level of 0.05 , so H9 is not true.

\section{Conclusion and Inspiration}

The theoretical contributions of this study have the following points. (1) This study expands the research on the quality contract flexibility and organizational quality performance to a certain extent, using cognitive paradoxes and controlling accidental quality knowledge leaks as mediating variables to create two complete different paths to explore the relationship between the quality contract flexibility and organizational quality performance to help to understand their relationship. (2) Introduce the quality knowledge distance as a moderator, and further study the relationship between the quality contract flexibility and organizational quality performance. (3) If the enterprise wants to improve the organizational quality performance through the quality contract flexibility, it can be realized by paradox cognition, controlling accidental quality knowledge leaks and quality knowledge distance.

The limitations and future survey directions of the study are as follows. (1) In analyzing the internal mechanism, this study paid attention to the mediating role of paradox cognition and controlling accidental knowledge leaks. Future investigation can introduce other mediating variables based on the survey Analyze, construct a multiple mediation model, explore the explanatory power changes of each mediating variable under different moderating variables, and further open the door to the impact of contract flexibility on organizational quality performance. (2) This study uses the method of bootstrap to analyze and find that there is no mediating effect between organizational decoupling and knowledge distance. A single method cannot comprehensively explain that there is really no interaction between the two, so in the future will use a variety of other methods to analyze.

\section{Acknowledgements}

This research is funded by national social science fund project (17CGL020).

\section{References}

[1] Chiara, N., Kokkaew, N. (2009) Risk Analysis of Contractual Flexibility in BOT Negotiations: A Quantitative Approach Using Risk Flexibility Theory. International Journal of Engineering and Management, 1(1), 71-79.

[2] Blake, D., Cairns, A. J. G., Dowd, K. (2019) Still Living with Mortality: The longevity Risk Transfer Market after One Decade. British Actuarial Journal.

[3] Nysten-Haarala, S., Lee, N., Lehto, J. (2010) Flexibility in Contract Terms and Contracting Processes. International Journal of Managing Projects in Business, 3(3), 462-478.

[4] Carlos, O.C., Rui, C.M. (2013) Flexible Contracts to Cope with Uncertainty in Public-private Partnerships. International Journal of Project Management, 31, 473-483.

[5] Levin, J., Tadelis, S. (2010) Contracting for Government Services: Theory and Evidence from U.S. Cities. The Journal of Industrial Economics, 58(3), 507-541.

[6] Steven, T. (2012) Public Procurement Ddesign: Lessons from the Private Sector. International Journal of Industrial Organization, 30, 297-302.

[7] Yaling, D., Peng, Y., Yilin, Y. (2014) Research on the Impact of Initial Trust on Project Management Performance: the Mediating Role of Contract Flexibility and Contract Rigidity. Forecast, 5, 23-29.

[8] Kujala, J., Haarala, S.N., Nuottila, J. (2015) Flexible Contracting in Project Business. International Journal of Managing Projects in Business, 8(1), 92.

[9] Lewis, M., Roehrich, J. (2017) Towards a Model of Governance in Complex (Product-Service) Inter-Organisational Systems. Social Science Electronic Publishing.

[10] Qiu, J., Zhang, Y. (2019) Wage Rigidity and Debt Financing: Evidence From Labor Contract Renewal During the Financial Crisis. Available at SSRN 3352042. 
[11] Branconi, C.V., Loch, C.H. (2004) Contracting for Major Projects: Eight Business Levers for Top Management. International Journal ofProject Management, 22(2), 119-130.

[12] Gazafroudi, A.S., Corchado, J. M., Keane,A . (2019) Decentralised Flexibility Management for EVs. IET Renewable Power Generation, 13(6), 952-960.

[13] Carson, S.J., Madhok, A., Wu, T. (2006) Uncertainty, Opportunism, and Governance: The Effects of Volatility and Ambiguity on Formal and Relational Contracting. Academy of Management Journal, 49(5), 1058-1077.

[14] Aghion, P., Tirole, J. (2007) Formal and Real Authority in Organizations. Journal of Political Economy, 105(1), $1-29$.

[15] Lei, Z. (2017) Research on the Impact of Contract Governance on the Performance of PPP Project Management. Beijing Jiaotong University.

[16] Bajari, P., Tadelis, S. (2001) Incentives Versus Transaction Costs:A Theory of Procurement Contracts. Band Journal of Economic, 2(3), 387-407.

[17] Susarla, A. (2012) Contractual Flexibility, Rent Seeking, and Renegotiation Design:An Empirical Analysis of Information Technology Outsouroing Contracts. Management Science, 58(7), 1388-1407.

[18] Cunha, M.P., Putnam, L.L. (2019) Paradox Theory and the Paradox of Success. Strategic organization, 17(1), 95-106.

[19] Fecher,N., Paquette-Smith,M., Johnson, E.K. (2019) Resolving the (Apparent) Talker Recognition Paradox in Developmental Speech Perception. Infancy, 24(4), 570-588.

[20] Hahn, T., Knight, E. (2019) The Ontology of Organizational Paradox: A Quantum Approach. Academy of Management Review.

[21] Smith, W.K., Tushman, M.L. (2005) Managing Strategic Contradictions: A Top Management Model for Managing Innovation Streams. Organization Science, 16, 522-536.

[22] Tihui, X. (2017) Research on the Impact of Cognitive Paradox of Senior Management Team on Corporate Strategic Decisions. Capital University of Economics and Business.

[23] Zesheng, W., Yi, Y., Zelong, W. (2018) Relationship between Paradox Cognition, Institutional Environment and Green Performance. Management Review, 30 (11), 76-85.

[24] Peng, M.W., Li, Y., Tian, L. (2016) Tian-Ren-Re Yi Strategy:An Eastern Perspective. Asia Pacific. Journal of Management, 33(3), 695-722.

[25] Chaudhary, R. (2019) Green Human Resource Management in Indian Automobile Industry. Journal of Global Responsibility.

[26] Smith, W.K., Lewis, M.W. (2011) Toward a Theory of Paradox:A Dynamic Equilibrium Model of Organizing. Academy of Management Review, 36(2), 381-403.

[27] Hahn, T., Preuss, L.,Pinkse, J. (2014) Cognitive Frames in Corporate Sustainability: Managerial Sense Making with Paradoxical and Business Case Frames. Academy of Management Review, 39(4), 463-487.

[28] Hart, O., Moore, J. (1988) Property Rights and the Nature of the Firm. Acta Crystallographica, 65(7), $250-254$.

[29] Grossman, S.J., Hart, O.D. (1986) The Costs and Benefits of Ownership: A Theory of Vertical and Lateral Integration. Journal of Political Economy, 94(4), 691-719.

[30] Inkpen, A., Minbaeva, D., Tsang, E.W.K. (2019) Unintentional, Unavoidable, and Beneficial Knowledge Leakage from the Multinational Enterprise. Journal of International Business Studies, 50(2), 250-260.

[31] Grossman, S.J., Stiglitz,J.E. (1980) On the Impossibility of Informationally Efficient Markets. American Economic Review, 70(3), 393-408.

[32] Kremer, H., Villamor, I., Aguinis, H. (2019) Innovation Leadership: Best-practice Recommendations for Promoting Employee Creativity, Voice, and Knowledge Sharing. Business Horizons, 62(1), 65-74.

[33] Li, L., Zhang, H. (2008) Confidentiality and Information Sharing in Supply Chain Coordination. Management Science, 54(8), 1467-1481.

[34] Mohamed, S., Mynors, D., Grantham, A. (2007) Understanding one Aspect of the Knowledge Leakage Concept among SMEs: People. International Journal of Electronic Business, 5(2), 204-219.

[35] Faisal, M.N., Banwet, D.K., Shankar, R. (2007) Information Risks Management in Supply Chain: An Assessment and Mitigation Framework. Journal of Enterprise Information Management, 20(6), 677-699.

[36] Wei, C., Cheng, P., Bai, Y. (2016) Cross-enterprise Knowledge Sharing, Knowledge Leakage and Innovation Performance. Technology Economy, 35(6), 1-7.

[37] Benlu, H., Liuyang, Z., Gupeng, Z. (2017) Research on the Relationship between Knowledge Transfer and Enterprise Innovation Performance Based on Environmental Turbulence. China Soft Science, 11, 17-164.

[38] Xiabing, W. (2019) Research on the Impact of Knowledge Governance on the Innovation Performance of High-tech Enterprises. Anhui University.

[39] Cummings, J.L., Teng, B.S. (2003) Transferring R\&D knowledge: The Key Factors Affecting Knowledge Transfer Success. Journal of Engineering and Technology Management, 20(1), 39-68. 
[40] Capaldo, A., Lavie, D., Messeni, P.A. (2017) Knowledge Maturity and the Scientific Value of Innovations: The Roles of Knowledge Distance and Adoption. Journal of Management, 43(2), 503-533.

[41] Lin, Y., Anping, Y. (2016) Enlightenment of Entrepreneur's Cognition on Corporate Strategic Change: The Mediating Effect of Knowledge Creation Process. Nankai Management Review, 19 (1), 120-133.

[42] Schulze, A., Brojerdi, G. J.C. (2012) The effect of the Distance between Partners' Knowledge Components on Collaborative Innovation. European Management Review, 9(2), 85-98.

[43] Zhixiong, X. (2014) Empirical Research on the Influence of Knowledge Distance on Knowledge Absorptive Capacity: Taking Service Outsourcing Enterprises as an Example. Information Science, 10(32), 61-69.

[44] Qian, Y., Liang, J., Dang, C. (2009) Knowledge Structure, Knowledge Granulation and Knowledge Distance in a Knowledge Base. International Journal of Approximate Reasoning, 50(1), 174-188.

[45] Tao, C., Tienan, W. (2013) Empirical Research on the Existence of Moderating Effects of Knowledge Distance, Environmental Uncertainty and Knowledge Sharing among Organizations. Scientific Research, 31(10), $1533-1534$.

[46] Xizheng, Z., Zhen, N. (2009) Research on Measuring Model of Knowledge Distance between Enterprises and Its Application. Science \& Technology Progress and Policy, 26(22), 161-162.

[47] Fangwei, Z., Haoyang, Song., Jinlan, Z., Peng, W. (2018) Concept Definition and Scale Development of Contract Flexibility in Construction Project. Journal of Engineering Management, 32(04), 116-120.

[48] Panshi, S. (2012) Research on Supply Chain Quality Management and Its Relationship with Quality Performance from the Perspective of Immunity. Jilin University.

[49] Zihanxin, L., Yanhua, L. (2019) Relationships between Uncontrollable External Knowledge Sharing, Accidental Knowledge Leakage and Breakthrough Innovation Performance. Science and Technology Management, 40, 122-133.

[50] Xiangdong, Z., Fuji, X. (2019) External Knowledge Network and Enterprise Technology Capability: The Moderating Role of Knowledge Distance. Science and Technology Management, 40, 76-93. 